\title{
FRACTURES OF THE CARPAL SCAPHOID
}

FRACTURES OF THE CARPAL SCAPHOID.

By ALAN H. TODD, Loxdon.

TuE great majority of the cases of fracture of the carpal scaphoid that present themselves in the wards or the out-patient department of Guy's Hospital are examples of old fracture, and the reason for attending is invariably the same, viz., that the wrist is not as good as it was, or as it should be, and that it interferes materially with the wage-earning capacity, either because it hurts, or is weak, or for both reasons. On inquiring into the history, it generally transpires that the case was not diagnosed as one of fracture at the time of the initial injury; usually it was regarded and treated as one of 'sprain'. In other words, it is only when serious sequelæ have arisen and failed to disappear even after some months or years of symptomatic treatment, that a correct diagnosis is generally made; and the acute fracture, as such, is very often missed. In the special Fracture Out-patient Department (where all ambulatory fractures are treated), such cases are comparatively rare; only 9 have been found there, in a consecutive series of 3000 cases of one sort and another. In this particular department, all cases of injury of the wrist, of whatsoever kind, are examined with the $x$ rays as a routine procedure, and a plate is always taken ; the wrist is examined anteroposteriorly and laterally, and sometimes obliquely as well, so that it is improbable that many cases of fracture of the scaphoid are overlooked. Moreover, since the writer's attention was first directed particularly to this class of case, the radiograms of all the Colles's fractures and other injuries in the neighbourhood of the wrist have been re-examined, and no example of fracture of the scaphoid has been discovered amongst them.

In the general surgical clinics, cases of recent fracture of the carpal scaphoid are practically never seen : it appears, therefore, to be justifiable to conclude that: (1) A number of recent cases of this fracture are overlooked, and either do not come to hospital at all, or else are to be sought for in the minor-casualty departments, being treated for 'sprain' or the like ; (2) When all cases of injury in the region of the wrist are $x$-rayed as a routine, with a good technique, fracture of the carpal scaphoid can always be detected. In other words, given a due appreciation of the likelihood of such an injury being present, and given also an opportunity for radiographic examination, there is no excuse for cases being wrongly diagnosed.

Without in any way condoning carelessness in the diagnosis of fractures in general, onc must admit that there are cases in which failure to detect that a fracture is present does not materially damage the patient, in so far as his ultimate functional result is concerned. In many cases of incomplete fracture, for example (such as were invariably overlooked until the advent of $x$ rays), a layman would probably be quite willing to use his limb as long as he regarded it as being merely sprained, and probably he would get a very good result in consequence. If, however, he knew that it had been fractured, he would regard the injury as being much more serious; even if it were only a fracture in the most technical sense of the phrase, he would be inclined to avoid using his limb, to anticipate pain and disability, and so on, and the ultimate result might very well be impaired in consequence. The public does not discriminate, as a rule, between various types and degrees of fracture; for them, a fracture is a fracture, and a very serious thing too. This pessimistic belief is unfortunately not altogether unjustified, for after all it is the conclusion that the public has arrived at in the light of bitter experience; they judge by results, by what they themselves have seen and experienced, and no one could deny that the results of fracture treatment in the past have often left much to be desired. 


\section{THE BRITISH JOURNAL OF SURGERY}

The factor of suggestion and autosuggestion is also a large one in determining the functional result after fracture. It is not many years since the medical profession generally was accustomed to encase the limb in rigid splints for a very long time after a fracture, and to enjoin perfect rest and various irksome restrictions; the whole atmosphere of the patient seemed almost to be designed so as to magnify the gravity of the injury. Even when the splints were taken off, there was a long period of after-treatment to be faced ; wasted muscles to be exercised, stiff joints to be moved, and adhesions to be painfully broken down. The ultimate result was not always good, and patients were told (and learned for themselves) that they must expect pain if they wanted to get a good result, or, perhaps, that they must expect always to have some physical disability. It is hardly to be wondered at, then, if the public look upon fractures rather pessimistically at the present time; their view-point to-day is the outcome of the way in which they were treated, and the things they were told, yesterday; tradition changes slowly. We have taught them to regard a fracture as being a very serious thing, usually associated with pain and disablement; therefore they expect them, and even if they are not always present they imagine them. That is to say, traumatic hysteria is very common after fractures; but it is quite preventable, partly by our doing much better work in the future than we did in the past, and partly by our educating the public up to quite a different conception of fractures.

But in the case of fractures of the carpal scaphoid there is no question of hysteria, or of any other form of suggestion or autosuggestion ; if a case is not properly diagnosed and treated, there will be serious disability, almost to a certainty, and probably it will be permanent. Medical writers are not given to recording their failures; yet the literature of fractured scaphoid teems with accounts of operations performed in the hope of mitigating the disability that has ensued on a 'missed' fracture. And these operations have not been very successful on the whole; for though many authors have claimed good results in individual cases, or in very small series of cases, yet a large number of different procedures have been described - a sure proof that no one method has shown itself to be really good. The majority of surgeons are very pessimistic concerning the prognosis in cases of old fracture of the scaphoid, with or without operation, and it would be difficult to find anyone who would guarantee to make a man's wrist normal again by operation, after such a fracture.

In all the cases of old fracture that the writer has seen, the complaint has been the same, viz., that the condition of the wrist was such that it interfered materially with the man's wage-earning capacity. Either it was painful, or it was weak, or it was liable to catch or to give way just as the patient was performing some muscular action; sometimes swelling was complained of, but generally it has been mechanical weakness or unreliability. All the Guy's cases have occurred in men of early adult age ; most of them have been mechanics. In this small series, as in all published cases, the majority of the fractures have occurred in the right hand. In every case, a definite history of the causal injury could be obtained without difficulty ; the man could say just when it happened, and what he was doing at the time; he was always quite clear as to the precise moment at which the damage was done, and there was no question of his merely presuming that an injury must have taken place, when he came to think the matter over in the light of subsequent experience. On the other hand, it was not always possible to ascertain the exact mechanism of the fracture, the patient having very often forgotten the precise position of the hand and wrist at the time. The most common account is that the man fell on to the outstretched palm, the wrist, of course, being hyperextended. Occasionally, the hyperextension is the result of a motor-engine back-firing, and not of a fall. At any rate, in those cases in which the fracture has resulted from overextension of the wrist, there has always been a considerable amount of force exerted ; fracture of the carpal scaphoid is never the result of a mild injury. The violence necessary to break the bone is such that it is very unlikely to be forgotten ; this is a point of much importance in connection with the much-debated question of bipartite scaphoid versus fracture (vide infra). In yet other cases a different kind of mechanism altogether seems to have come 


\section{FRACTURES OF THE CARPAL SCAPHOID}

into play; in certain instances, for example, the bone has apparently been broken with the wrist hyperflexed, and certain writers regard this as the normal mechanism of fracture; in the present series, however, hyperextension together with the exercise of considerable violence appears to have been the usual mechanism.

The first step, then, towards the diagnosis of fracture of the carpal scaphoid consists in eliciting the history of the causal injury, which is very definite and characteristic.

The next point is to make out what the results of this injury were. These also are very definite, and appear to the writer to be both striking and characteristic. 'The first sign, as a rule, is swelling; it appears almost at once, and is most marked in the region known as the 'anatomical snuff-box'; it is never great, and it is never very widespread ; the tendons which form the boundaries of the snuff-box may be obscured, and the odema may sometimes spread a little way upwards, tending rather to follow the line of the lower end of the radius; but it never surrounds the whole wrist, and it seldom even extends right across the back of it. Very seldom indeed does it travel down the back of the hand towards the base of the index finger. The folds at the wrist are never obliterated. In short, the swelling takes the form of a rapid, localized cedema on the dorsum of the radial half of the wrist-joint (Fig. 1). In true sprain of the wrist (by which should be meant traumatic synovitis of the wrist-joint, and no other condition), the swelling is much greater in amount, and much more diffuse. But the chief point to emphasize in connection with 'sprained wrist' is that it is an excessively rare condition-so rare, in fact, that many surgeons who have great experience of fractures doubt its very existence. As Speese ${ }^{64}$ well says, "Sprain of the wrist is a diagnosis which is less and less tenable". If only this fact were as fully appreciated as it should be, a very large number of fractures of various kinds (not to mention other important injuries, such as dislocations of various carpal bones, especially the semilunar) would be discovered, and much pro-

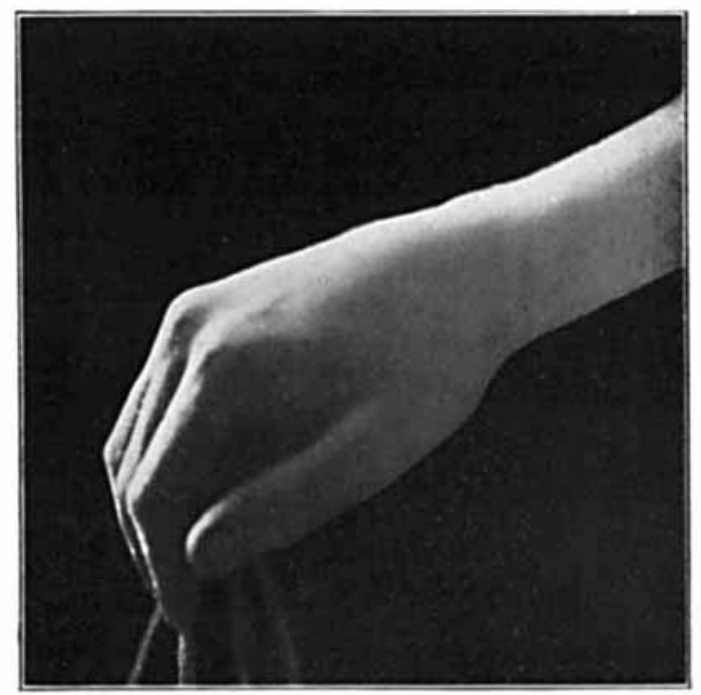

Fig. 1.....'The typical oedema of a case of fractured scaphoirl. longation of disability and depreciation of earning capacity would be avoided in consequence. It is extraordinary that the diagnosis of sprained wrist is so commonly made, when as a matter of fact the injury so rarely occurs. In tenosynovitis, such as sometimes follows a violent wrench of the wrist, there is swelling, but this is usually all about the extensor tendons, and extends right across the back of the wrist, whilst the snuff-box is not particularly swollen. Moreover, the typical soft crepitation that characterizes tenosynovitis is always very easily perceptible when the examiner's fingers are placed flat upon the back of the wrist and the joint is then moved to and fro.

In the early stages the swelling is ordinary soft oedema; if the case is recognized as one of fracture of the scaphoid, and is skilfully treated, it will probably disappear. But if it is overlooked or neglected, some part of the swelling will almost certainly persist for years afterwards ; in any case of 'missed' fracture, it is always possible to detect some fullness in the snuff-box, whilst the tendons defining that space are a little less obvious than they are on the uninjured side. At this late stage the swelling is not purely oedema, of course ; some of it is due to actual organic thickening; but a part is still caused by odema, set up, presumably, by the effect of moving the arthritic joint. At operation it 
is usually quite easy to demonstrate these two elements that go to make up the chronic swelling, viz., the cedema and the organized inflammatory material.

Ecchymosis is extremely rare in fractures of the scaphoid, because rupture of the capsule of the wrist-joint is very rare in these cases, whereas in severe contusion of the tissues about the joint ecchymosis is both common and widespread.

So much for what may be seen by a mere inspection of the wrist at rest. We come now to palpation. A careful observer will make his diagnosis practically without having to move the wrist at all ; at any rate it need only be moved a very little, and it is never necessary to put the patient to any severe pain in order to ascertain that a fracture of the scaphoid has occurred, no matter whether the case be a recent or a late one. The first point that will be ascertained is that there is acute local tenderness; this is situated just beyond the radial styloid process, in the anatomical snuff-box; it is, in fact, just over the proximal fragment of the scaphoid. Special care should be taken in defining the exact site of the tenderness, for it is an important point in the differential diagnosis ; for instance,

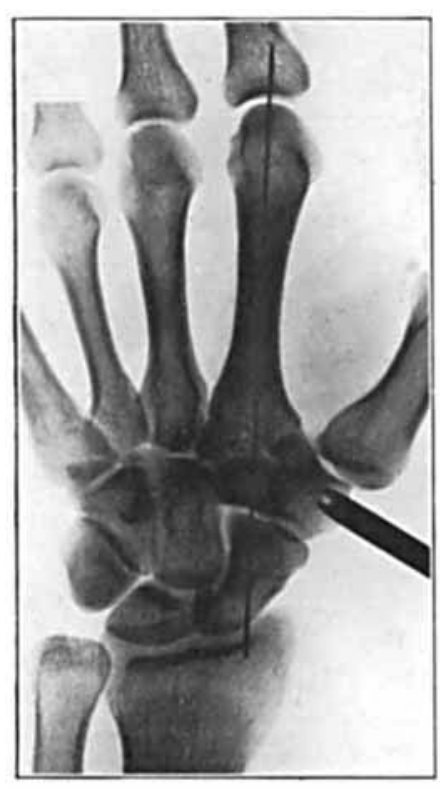

Thic. 2.--Slowing the transmiscion directly to the seaphois of the coree of a blow applied to head of second netacarpal. in fracture of the radial styloid process itself, the tenderness is a little higher up, and more on the outer border of the limb, whilst in Colles's fracture the line of tenderness is again over the exact site of fracture, i.e., some $\frac{3}{4}$ in. above the lower articular surface of the radius. In fact, as J. B. Murphy ${ }^{47}$ puts it, " the first stage of the diagnosis is the appreciation of the fact that the injury is substyloid". The mere fact, however, that a person is tender in the snuff-box, and that such tenderness is limited to the region of the snuff-box, is not enough to warrant a diagnosis of fracture of the scaphoid. In recent eases, of course, there will be the oedema, and the pain and the impairment of function, to make the diagnosis clear; but in old cases there may be a possibility of mistake. Every one is tender, to some extent, in the proximal half of the anatomical snuff-box, because that is just where the dorsal branch of the radial nerve runs, and firm pressure there is capable of injuring it. But it is quite easy to distinguish radial-nerve pain from fractured-scaphoid pain, because the nerve-pain is not nearly so acute as the pain that is associated with fracture (even old fracture), and it becomes less after a few moments during which the pressure is maintained, because pressure-anæsthesia supervenes; in the case of fracture, however, the pain becomes unbearable. Moreover, the nerve-tenderness can be elicited in either wrist by an equal amount of pressure, whereas the fracture-tenderness is presumably unilateral as a rule. In recent cases the tenderness of the fracture is considerable; one author describes it as a 'wincing' tenderness, and this is a very good description, which gives a very accurate and graphic impression of what one sees in such cases.

Another valuable method of eliciting the tenderness is by means of the application of force at a distance, i.e., the indirect jarring of the site of fracture. This is the principle involved in Vaughan's knuckle-percussion test. The metacarpophalangeal joints are all flexed to a right angle, or, if possible, the patient is made to clench his fist; he is then told to keep his eyes shut, whilst the surgeon taps the knuckles smartly, one after another, with an ordinary rubber-headed knee-jerk hammer. If fracture of the scaphoid is present, sharp pain will be elicited when the head of the second metacarpal is struck, but not when any of the others is struck; Fig. 2 shows quite clearly that the force of a blow upon the end of the second metacarpal would be transmitted directly along the bone to the trapezoid and scaphoid, whereas a blow on any of the others would be dissipated before it could 


\section{FRACTURES OF THE CARPAL SCAPHOID}

reach the scaphoid. Incidentally, it may be pointed out that it would be the third metacarpal that would be tender in cases of fracture of the semilunar. This point is sometimes helpful in the differential diagnosis, either before $x$-ray examination or in places where an $x$-ray apparatus is not available. Vaughan's test is very reliable when it is positive, but it is not invariably present; in the first few days after a fracture it can generally be demonstrated without difficulty; but a week or more after the date of injury, some patients will allow the second metacarpal to be quite sensibly jarred without making any complaint.

In the acute stage, the typical swelling, the severe pain that is made worse by every sort of movement, the acute tenderness just over the scaphoid distal to the radial styloid process, and the limitation of movement, especially of dorsiflexion of the wrist, make up a picture that is so absolutely characteristic that it is always possible to diagnose fracture of the scaphoid with perfect confidence; it is incredible that anyone who is conversant with the physical signs of this fracture could ever miss a case. The only possible explanation for the marked preponderance of 'missed' cases over recent cases is that these signs are not familiar to the generality of practitioners. In view of the very grave disability that ensues when a fracture of the scaphoid is overlooked, however, it is clearly of great importance that the attention of the rank and file of our profession should be drawn to this fracture, and to its diagnosis and treatment.

Even in a late case the typical swelling is not always totally absent; some trace of it is often to be observed, in the form of a pulfiness in the region of the snuff-box. Tenderness, too, can sometimes be elicited; if the fragments of the scaphoid are completely ununited, or if the bone has united with excess of callus, there may be definite local tenderness on pressure directly over the bone. Any attempt, moreover, to extend the wrist beyond its ordinary range will result in pain.

Limitation of extension of the wrist-joint is present from the first. If perfect gentleness is exercised in the clinical examination, it is usually possible to get a man with a fractured scaphoid to flex his wrist, but by no means can he be induced to extend the joint to more than $45^{\circ}$ at the very most ; nor should one persist in trying, for the mere fact that extension is markedly limited and painful tells us all that we need to know. In late cases the limitation still persists; even after the lapse of some years any attempt to thrust the wrist forcibly back to the normal extent will cause pain. It scems probable that this pain is mainly a referred pain, whilst the limitation of movement is ehiefly caused by muscular spasm, for the pain and limitation are mostly observed in those cases in which there is an actual arthritis present, and the limitation disappears entirely under anxsthesia ; if it were due to adhesions, this would not be the case. In other words, even the late rigidity and limitation of movement (extension) are to be regarded as being largely protective mechanisms.

To conclude the clinical examination of the patient, two minor points in the differential diagnosis may be noted : firstly, that the measurements of the two limbs are exactly the same (which would not be the case in a typical Colles's fracture, for example), and, secondly, that there is no muscular wasting at any stage.

It is only since the advent of $x$ rays that fractures of the carpal bones have been recognized at all. In fact, there is practically no literature at all upon the subject prior to the year 1900 ; Hamilton dismisses the subject with the remark that of course the carpus may be involved in severe crushes of the whole limb; whilst other large and authoritative works have nothing to say about the subject at all. Stimson, in 1900 , wrote that crepitation was the one cardinal sign, whereas as a matter of fact it never occurs.

Radiography should, of course, be employed as a routine in the examination of every case of injury in the region of the wrist; by this means many obscure cases will be rendered perfectly clear, and a vague and unconvincing diagnosis will be converted into a precise and satisfactory one. Practically every case of so-called 'sprain' of the wrist will be found to be in reality something else, and one may justifiably paraphrase Punch's famous advice, and say, "To those about to diagnose sprained wrist,-Don't". When damaged wrists are $x$-rayed as a routine, fractures of the carpus are not overlooked, for 
with a proper technique they are quite easy to detect; it is because these cases are not always radiographed that mistakes occur, and that we mect with so many overlooked fractures. As we observed in our opening paragraph, it is not in the special fracture departments of our hospitals that we meet with the 'missed' cases, but in the minor dressing rooms, casualty departments, and so on.

We have said that fractures of the scaphoid are easy to detect, provided that a proper tcchnique is cmployed. As a corollary to this, one should hasten to add that without a proper technique it is very easy to overlook a fracture, or to diagnose fracture where none
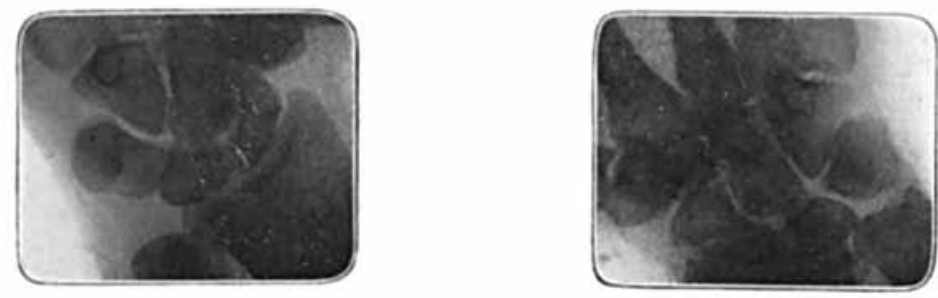

Fias. \& \& 4.-Fale shatow, due to bud centration of $x$-ray tube.

exists. In the first place, the shape of the scaphoid varies somewhat in different persons, according to their age, occupation, and so on. But what is far more important is that very great variations in the apparent shape of the bone may result from variations in the position of the hand, or of the fluorescent tube as compared with the hand, at the time when the radiogram is being taken. Figs. 5 and

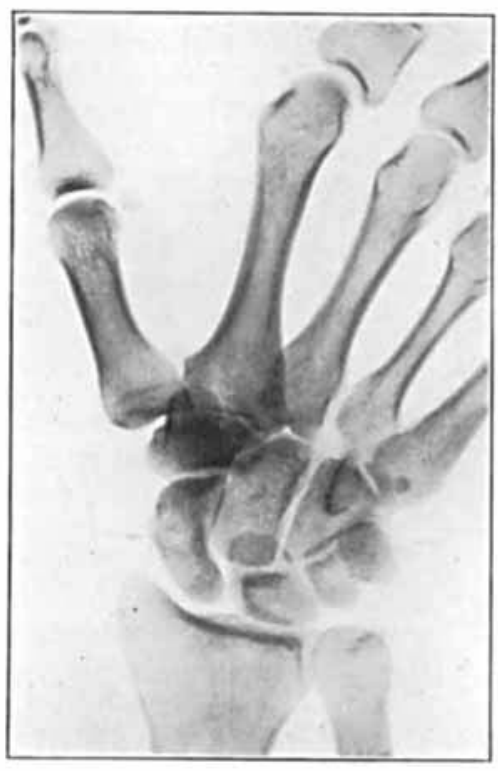

IFI. 5.-Norma] carpus in adduction, or ulnar dellection. 8 illustrate this point very clearly, whilst Figs. 3 and 4 are two instances, picked at random out of a large number of $x$-ray pictures of the carpus, to show how imperfect centration may vitiate the shadow obtained. It is evident from the most cursory examination of these radingrams that the best view of the bone is obtained when the hand is in the position of ulnar deflection, as in Figs. 5 and 6 ; even when the hand is held normally in line with the forearm the scaphoid is very clearly seen, but here the foreshortened view of the tuberosity of the bone begins to be apparent; when the hand is in the position of radial deflection, as in Fig. 8, the tuberosity stands out very clearly as a sort of second shadow superimposed upon the normal thickness of the bone. Very often the outline of the tuberosity does not coincide accurately with that of the rest of the bone, and thus there is produced an appearance of a notch on the outer border of the bone; this is very frequently diagnosed by the uninitiated as a fracture, but by carefully scrutinizing the lower articular surface of the bone, i.e., that for the os magnum, it will be seen that there is no evidence of fracture there (Figs. 9 and 10). Occasionally the notch-like border of the tuberosity has been described as evidence of a compressionfracture of the edge of the scaphoid produced by impaction upon the styloid process of the radius, but this is simply a misinterpretation of radiographic appearances; such a fracture does not oceur. 


\section{FRACTURES OF THE CARPAL SCAPHOID 13}

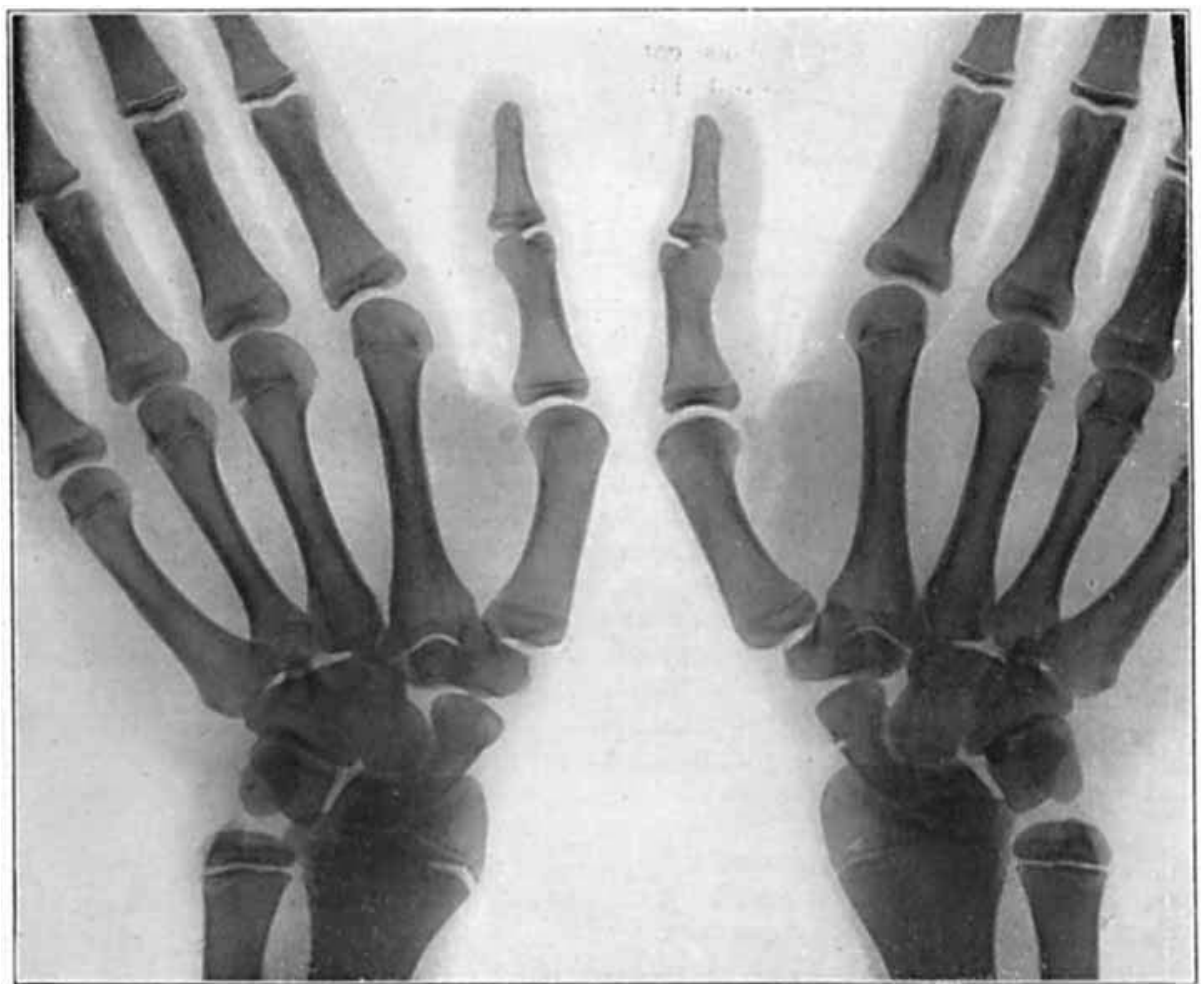

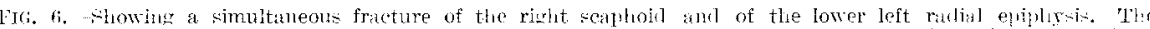

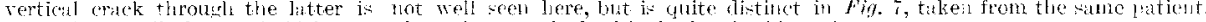

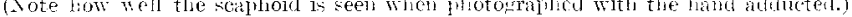

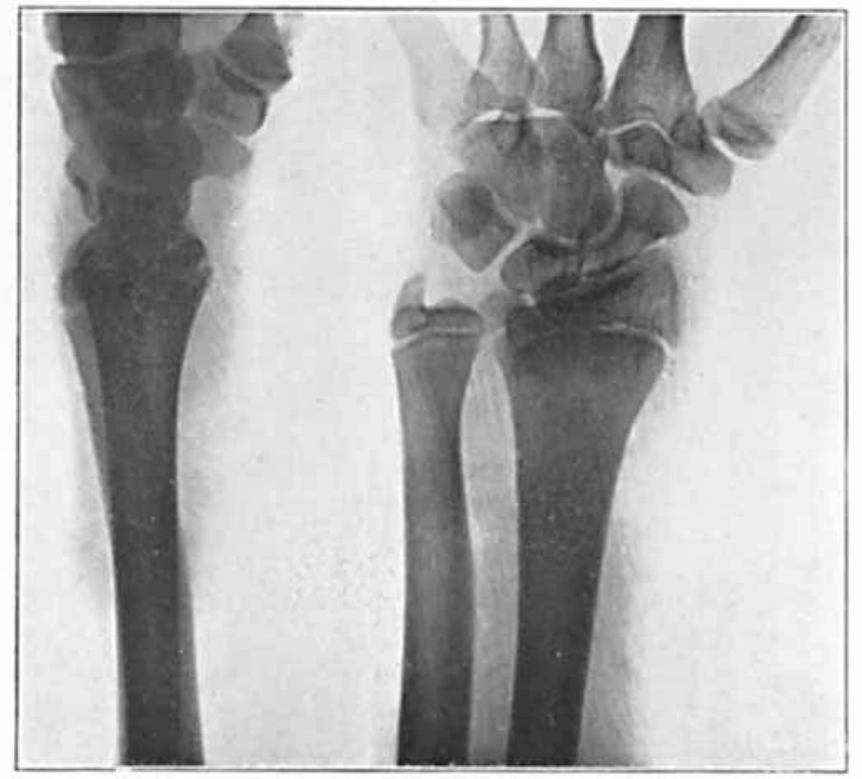

Fig, T.-Fracture of right seaphoil, and rertial crack throuch lower epinuris of left ratilus.

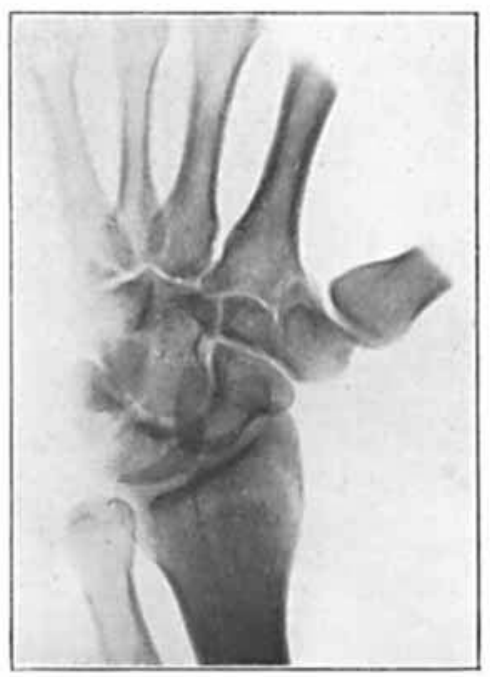

FIC. S.--Nornal carnil, in abluction. or ritlinl letection. 


\section{THE BRITISH JOURNAL OF SURGERY}

Codman and Chase, ${ }^{11}$ in their elassical article in the Annals of Surgery for 1905, lay down a precise technique to be adopted in $x$-raying cases of fractured scaphoid, or sus-

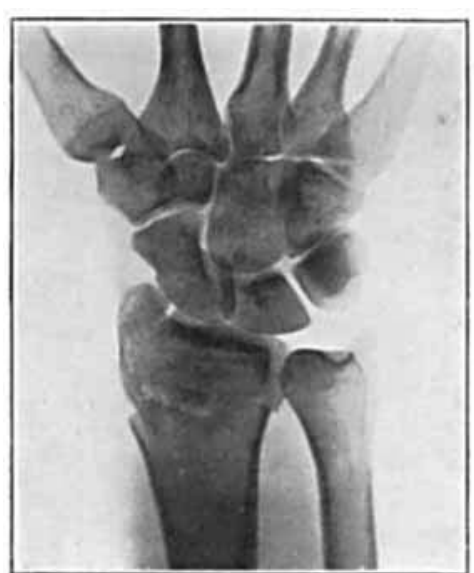

Frs, 9.-A 'notched' scaphoid, i.e., a view in which the foreshortened tuberosity is superimposed apon the shadow of the remainder of the bone. pected cases of that injury; they say that the two hands should be placed side by side, palms downwards, and with the thumbs as close together as possible; the hands should be as much ulnar-deflected as possible, the tube placed on a level with the knuckles, and in this position the photograph should be taken (Fig. 6). Further, views should be taken with the palms supinated. It is hardly necessary to add that plates should always be taken; mere examination with the fluoroscopic screen is totally unreliable for the detection of these fractures in all cases. Nevertheless, in a doubtful case, screen-examination should be employed as an adjunct to the taking of plates, and for this reason : the line of fracture, when the bone is broken through the waist, as it usually is, is not always just at right angles to the surface of the couch and to the incident ray, even when the hand is held in the standard position. The rays therefore have to travel through a normal thickness of bone, and the existence of a linear fracture may quite casily be overlooked in consequence. If, however, the wrist is slowly turned from the fully-supinated to the fully-pronated position, there must be, at some stage, a moment when the rays will pass through the small space between the fragments, and at this moment the observer will see a bright band of light on the screen. (This applies, of course, only to recent fractures, before callus-formation has taken place.) (Figs. 11-13.)

The proper routine to be observed, then, in $x$-raying a recent fracture of the scaphoid, consists in : (1) Fluoroscopy, in all positions between full supination and full pronation;

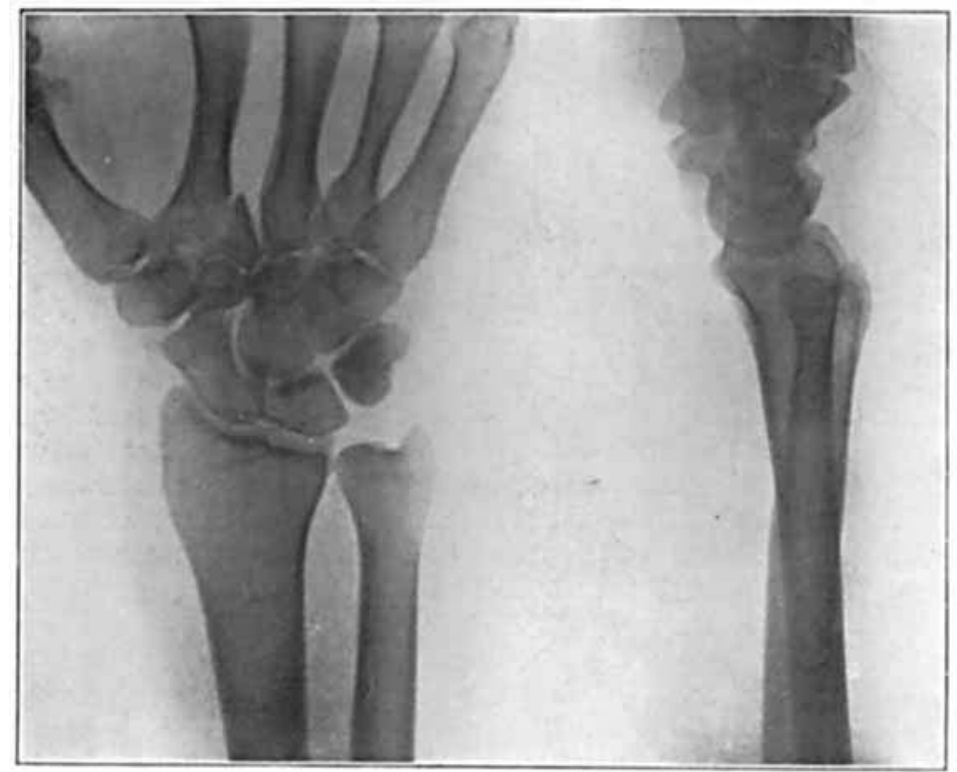

Fa. 10.-Vialle's fracture, i.e., fructure of posterior lip of lower end of radins by force transmitted througl the scaplioin. 


\section{FRACTURES OF THE CARPAL SCAPHOID}

(2) Taking plates of both wrists, in Codman and Chase's standard position, one set with the palms turned up, and the other set with the palms turned down; (3) Occasionally, when the fracture of the scaphoid is merely part of a complicated injury of the carpus, it may be well to take stereoscopic pictures of the wrist; in such a view the bones stand out very perfectly in relief, and a very beautiful view of the carpal tunnel is secured.

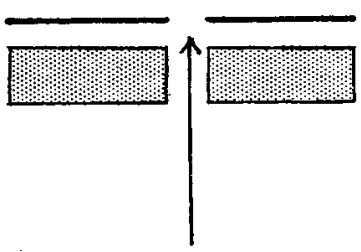

FIt. 11.- Diarram showing how the x-ray pasiluer vertically throunh a fricture of the scaplioid produce 1. clear banul of lictit across the Gadow on the screen.

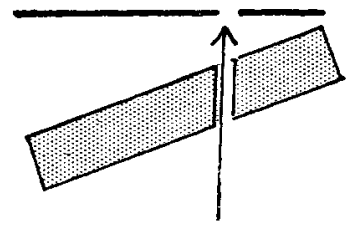

Fig. 1.2. Show's how oblitue fracture ean be demontrated by rotating wrist.

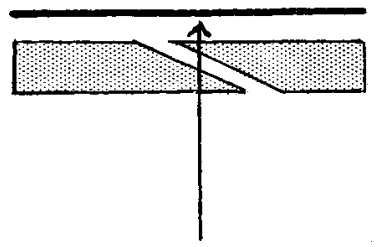

Fit. 13.- - Show that no elea. hand will be seen if the incident ray does not lass vertically throush fracture.

This discussion on the radiography of the scaphoid leads up to the question of variations in the position of the scaphoid in accordance with variations in the position of the hand as a whole. This is of more than merely academic or radiological importance, for it has a very practical bearing upon the mechanism of the production of fracture, or, rather, of the various fractures. The question has been studied by dissections, both in the cadaver and in the living patient, but by far the best idea can be obtained by carefully studying a series of stereoscopic views of the carpus, taken in various positions. To anyone who has not tried this method, it will come as a revelation; the views obtainable are very beautiful, and give one a wholly new conception of what happens to the various parts of the carpus during various movements. Moreover, the results thus obtained are necessarily much more reliable than those obtained under the very artificial conditions of dead-house dissection, where all the surrounding soft parts have to be cut away before the bones can be studied.

The first and most obvious fact that we note about the movements of the scaphoid is, that when the hand is radially deflected (or abducted) it slides well under cover of the lower articular surface of the radius (Fig. 8), whilst when the hand is ulnar deflected (or adducted) the scaphoid is dragged out of this cover, and becomes perhaps more exposed to injury (Fig. 5). In many radiograms it cven appears that the scaphoid tends to leave the radius, so that there is a clear space seen between the lower border of the radius and the upper border of the scaphoid, whilst there is evidently an ample radiocarpal space in which the scaphoid can lie (Fig. 5).

When the hand is radially deflected, however, the seaphoid is thrust up against the radius, and the radiocarpal space for the bone is minimal. Over and above the purely lateral movement of the seaphoid, Nogier ${ }^{48}$ has described a 'pseudo-luxation' of the bone, by

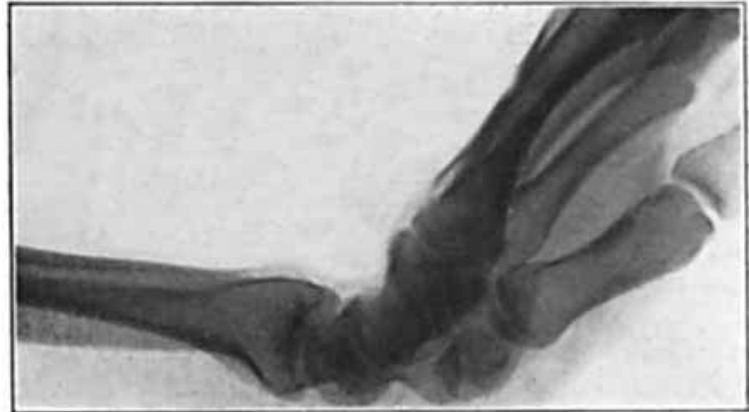

Fif. 14.--Normal campus, in extension. which he means an anteroposterior tilting of the scaphoid during radial deflection; the bone tilts in a dorsi-palmar direction, so that the tuberosity comes forward and appears much more foreshortened than it really is ; in other words, in abduction of the wrist the scaphoid comes to lie much more nearly 
at a right angle with the long axis of the forearm than it normally does. (In its normal position, it makes an angle of about $45^{\circ}$ with the long axis.) This increased tilting of the bone with radial deflection of the wrist explains of course the superimposing of the shadow of the tuberosity upon that of the body of the bone, as explained above (Figs. 8, 9, and especially Fig. 24). If the wrist-joint be extended, the tilting goes a stage further, and the scaphoid comes to be practically perpendicular to the long axis of the forcarm, and lies in close contact with the lower articular surface of the radius and its styloid process (Fig. 14).

From a study of the radiograms here reproduced it is easy to see that, in all positions of the wrist, the body of the seaphoid continues to act as a buffer between the os magnum and the radius, and to transmit force to the radius from the outer column of the carpus and metacarpus; however much it may project, at least the bone never escapes from its radiocarpal pocket. In certain positions the body of the bone must obviously be pinned very securely between the radius on the one side and the os magnum on the other, whilst the projecting tuberosity is subjected to various forces, direct or indirect, by which fracture may be produced. Moreover, the scaphoid is adapted to act as a buffer, not only because of its position, but also in virtue of its very structure, for it is mechanically weaker than either the radius or the os magnum; it serves admirably, therefore, to dissipate force transmitted through it, but is liable to suffer in the process. In order to allow of a certain amount of gliding during this force-dissipating or force-distributing process, the scaphoid is left by nature comparatively free from attachments : it is anchored to the os magnum and to the semilunar by an interosseous ligament; but it is quite free from the trapezium, the trapezoid, and the radius, whilst none of the thenar or any other muscles are attached to it, and the anterior annular ligament is attached only to the proximal part of it. We shall see, later, that this comparative detachment from neighbouring structures, though no doubt it has its advantages, has also a great deal to do with the marked tendency to non-union which fractures of this bone display.

There has been much acrimonious diseussion as to whether all those cases in which a radiogram clearly shows a partition of the scaphoid are really cases of fracture. Many authorities maintain that there exists a condition of bipartite scaphoid, which is quite independent of fracture, and is probably a developmental freak. Their opponents contend that all the eases described as bipartite scaphoids are really cases of old ununited fracture. No doubt fracture of the scaphoid does frequently oceur in cases diagnosed and treated as sprains of the wrist, and non-union inevitably follows; a pseudarthrosis develops between the fragments, and if there is little or no callus exuberance, and little arthritis, it is very easy indeed to mistake the radiographic appearances for those of bipartite scaphoid. It is assumed that in many of the cases described as bipartite scaphoid there was really a fracture, and that the accident has been forgotten. But even allowing for the extraordinary stupidity and forgetfulness of some classes of patient (so that one has even seen cases of bony ankylosis of the hip in wlich no history of previous pain or illness could be extracted), it is almost inconceivable that a grown-up person could completely forget the accident that would lead to a fracture of the carpus. The youngest age at which this fracture has been recorded is 15 years, and the average age is 24 years. It must not be forgotten that these fractures only occur in adults, and only after considerable violence. Nevertheless, it cannot be denied that nearly all the 'bipartite scaphoids' that have been described have been found in cadavera, and that a routine search amongst live patients, by means of the $x$ rays, fails to reveal the condition in anything approaching the frequency which the champions of the bipartite bone assert to be normal. 'They say that bipartite scaphoid occurs in $\frac{1}{2}$ per cent of normal human beings, and that the bone is partly cleft in as many as 2 per cent. In not one of all the radiograms examined in connection with this article has any example been found, nor can I remember ever to have seen one whilst examining wrists with the $x$ rays for any purpose whatsoever.

But though we may not concede that partition of the scaphoid is common, we can hardly deny that it sometimes occurs. There is much evidence, hard to controvert, to show that it does. In the first place, partition of the scaphoid is almost always bilateral, 


\section{FRACTURES OF THE CARPAL SCAPHOID}

whereas fracture of the scaphoid rarely is (only 1 in 18 cases). Next, it has been demonstrated by quite a number of independent observers, including Rambaud, Rénault, Bardeleben, and Thilénius, that there are often two, and occasionally even three, ossific centres in a human scaphoid; normally these unite and form one, which is clearly seen with $x$ rays at six years of age, but remains cartilaginous and cushion-like up to sixteen years, and then begins to ossify throughout. It is easy to appreciate that sometimes these separate ossific centres might fail to unite in the ordinary way; sometimes they fail entirely, when the condition of bipartite scaphoid is produced, and sometimes they fail partially, when there is produced a cleft or notched scaphoid. The statement that the scaphoid might sometimes be bipartite seems to have been made first of all by Wenzel Grüber, in 1865; but the first really authoritative work on the subject was that of Pfitzner, published in 1900 ; he investigated 1456 wrists from this particular point of view, and found amongst them 9 cases in which the scaphoid was completely bipartite ( 7 left and 2 right), and 29 cases in which it was partially cleft (15 left and 14 right). In these cases, the outer bone articulates with the os magnum, trapezium, and trapezoid, and the inner articulates with the radius, semilunar, and os magnum; this arrangement is constant. The outer part is to be regarded as the true scaphoid, and the inner as a metascaphoid. Sometimes there is an os centrale as well in these cases, and it may either be present as a separate bone, or may be fused partly or completely with the radial or true scaphoid. In Pfitzner's article will be found a full bibliography of bipartite scaphoid. It also includes a romantic account of the discovery of the first os centrale; the distinguished morphologist, Dwight, had prophesied its existence long before any example of it had been found, basing his assertion on studies in comparative anatomy, and on the examination of the carpus in the skeletons of prehistoric men; years later, the os centrale was discovered by the aid of $x$ rays in a living man's hand. The whole story reminds one of the foretelling of the existence of various chemical elements and their physical properties from a study of the atomic series, and the ultimate discovery of each of them. The existence of iodine, for example, and its properties, were forecasted successfully in this way, and the same is true of several of the rare metals lately discovered.

Pfitzner worked out a sort of schema of the human wrist, in which there appears not only an os centrale, but also an os scaphoideum radiale and an os scaphoideum ulnare; this schema was based on comparative anatomy. The os centrale has been shown to exist; enthusiasts will probably say that this is an argument in favour of the other bones also existing, and they will say that the bipartite scaphoid is the living representation of the theoretical os scaphoideum radiale and the os scaphoideum ulnare. In actual fact, however, the bipartite scaphoid has not been demonstrated as often as one would have expected; Pfitzner says that he found the bone completely cleft in $\frac{1}{2}$ per cent of all wrists examined in his series of 1456 ; Codman and Chase, ${ }^{11}$ however, " did not find a single divided scaphoid that was not definitely associated with injury" in a series of 1040 wrists that they examined. They therefore consider that bipartite scaphoid is so rare that it cannot be held to account for the comparatively common cases of apparent fracture (amounting to $\frac{1}{2}$ per cent of all fractures, in fact). Another important point is that, at operation, the adjacent surfaces of the bones are always found to be rough, and to consist of cancellous bone ; whereas, in true bipartite scaphoid, articular cartilage would always be found elothing them, and it would be perfectly smooth and glistening.

'The lack of confirmation for Pfitzner's findings is a very telling point against those who believe in bipartite scaphoid, for an ounce of practice is worth a pound of theorizing ; nevertheless, there are certain other points to be borne in mind which support their claims to some extent: (1) The condition is sometimes associated with other developmental anomalies, such as webbing of the fingers, premature synostosis of the phalanges. If one developmental peculiarity exists, it rather strengthens the belief that any other abnormality present is of developmental origin also. (2) In a fair proportion of cases (though not in many of Pfitzner's) the condition seen is bilateral, whereas bilateral fracture of the scaphoid is admitted by every one to be exceedingly uncommon.

(3) Complete absence of any history of injury-we have dealt with this point above.

VOL. IX.-NO. 33 . 
To sum up, I think we must admit that the evidence is so strong, and the arguments are so good, that one cannot deny that partition of the scaphoid does sometimes occur as a developmental reversion; but it is probable that many, and perhaps most, of the cases actually described have been ordinary cases of 'missed' fracture of the scaphoid. The truth lies, as usual, midway between the two extreme views that have been put forward.

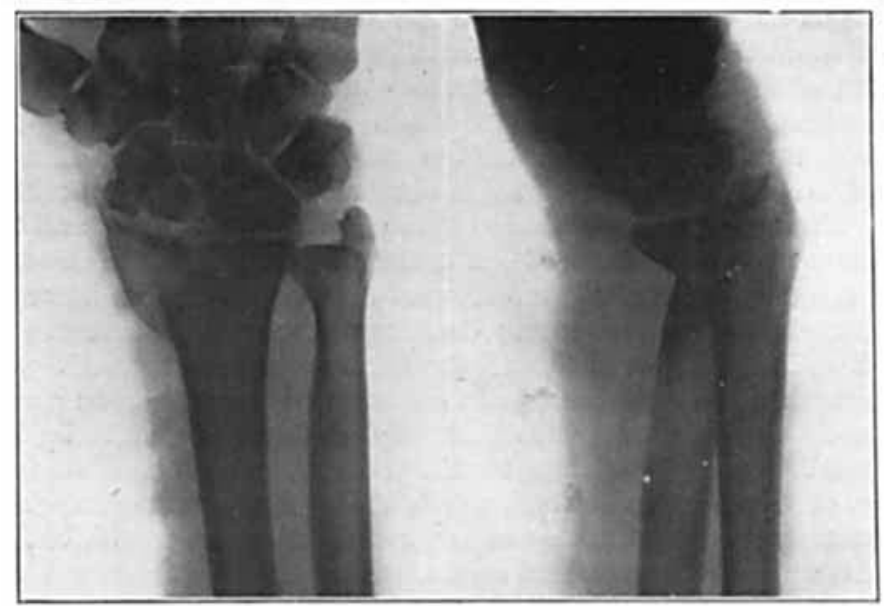

FIG. 15.-Comminuted scaphoid and obligue fracture of lower end of radius (involving articular surface). Anteversion of frizment. Direct injury.

Next, let us study the radiographic appearances of the various types of fracture that occur, and consider how they are produced. 'The ordinary text-books talk about 'fracture' of the scaphoid, but there are in reality several perfectly distinct varieties; this is why the present article has been entitled, "Fractures (and not Fracture) of the Scaphoid".
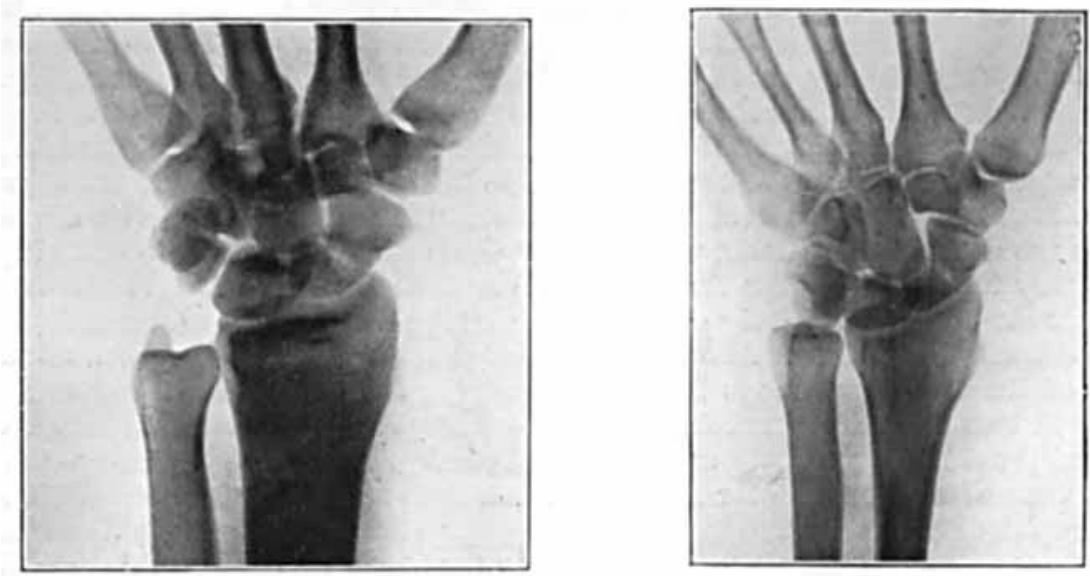

FIGs. 16, 17.-Transverse or 'sllapped-waist' fracture of scaphoid, produced in abducted position of carpms, as always.

The several types connote several different mechanisms, and, armed with a precise knowledge of the normal anatomy and function of the scaphoid, it should not prove difficult to work out these mechanisms.

The commonest fracture is a clean snap across the waist of the bone. Usually the 
break is at the middle of the bone, which is its slenderest part, but sometimes it is nearer to one or other end. Obviously this difference depends upon the position in which the bone (i.e., the carpus) happens to be held at the time of the injury. It is also evident that the fracture must be produced by an indirect force, of the snapping variety, and not by a crush or other direct injury, One part of the bone, presumably, must be tightly gripped, whilst force is being applied to the other part. Two-thirds of all fractures of the scaphoid are of this 'snapped-waist' variety (66 per cent to be precise) (Figs. 6, 16, 17, 18). When a clear account of the accident can be obtained, it is always to the effect that the hand was abducted at the time. We saw, it will be remembered, that when the hand was abducted, the scaphoid was firmly jammed between the os magnum on the one side and the lower end of the radius on the other; also, we saw that in this position the scaphoid became more or less vertical, and whilst in this position it served as a buffer to dissipate force applied to the distal part of the hand, i.e., the carpus or metacarpus. The dorsal part of the bone is very firmly held, but the palmar end is held less firmly, and projects somewhat from the radiocarpal socket (Figs. 6 and 16); therefore the scaphoid yields at its weakest point, viz., the middle. In other words, the line of fracture usually continues the midcarpal interline. If abduction is less extreme at the moment

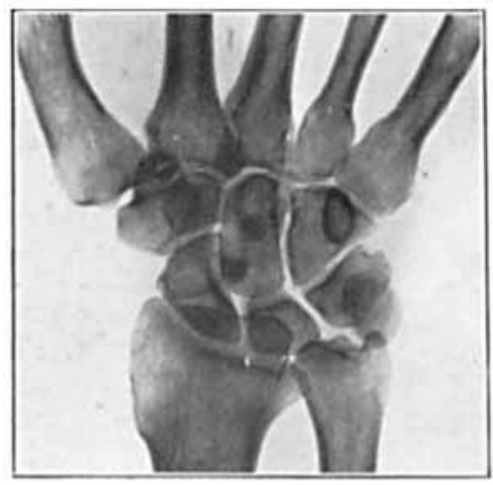

Fli. 18.-Old fracture of waist of scaphoil. of impact, the fracture will be nearer to the ulnar end of the bone. A fall upon the outstretched hand is the commonest type of accident, but backfires when starting up motor cars are sometimes held responsible. At any rate, the violence is always applied indirectly. Of all the authors who have written on fractures of the scaphoid, de Fortunet alone thinks that direct injury (Fig. 19) is a common mechanism, and certainly it cannot be the mechanism of the snapped-waist variety, which is the commonest fracture. Speese ${ }^{64}$ talks of two kinds of transverse fracture

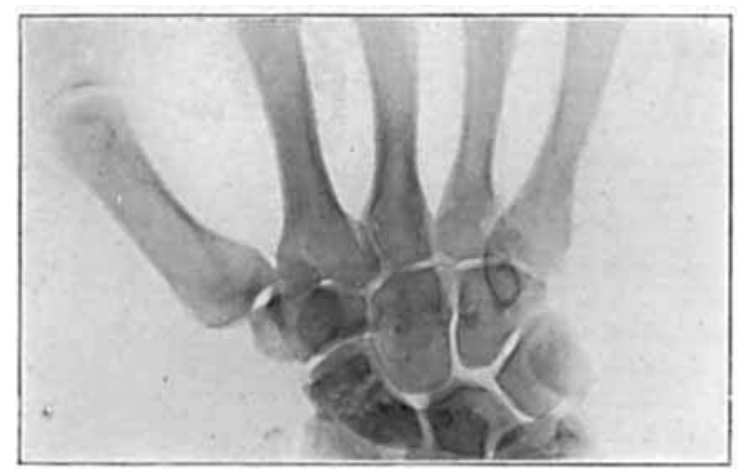

Fir. 19.-Comminuted fracture, produced by direct injury. (j.e., 'split-waist' fractures), one associated with compression, and the other without it. It is conceivable that at the extreme limit of radial deflection of the hand the scaphoid might impact upon the styloid process of the radius (Fig. 8 ), and, if it failed to break it, it might itself be somewhat crushed together and compressed in the process; but this seems improbable when we recall the vertical pseudoJuxation which occurs in the scaphoid in this position. It is far more likely that the apparent 'compression' is simply callus resulting from the repair of an ordinary transverse fracture. I have yet to see a recent fracture of the scaphoid, produced during abduction of the hand, in which the immediate radiogram shows any sign of compression.

Radial deflection of the hand, together with some degree of extension of the wristjoint (such as occurs in falls upon the outstretched palm), is responsible not only for transverse fracture of the scaphoid, but also for a certain fracture of the radius which, as far as $I$ can discover, was first accurately described by Vialle, of Lyons. I mean the very 
characteristic fracture of the posterior lip of the lower articular surface of the radius; it is a fracture which is very constant in type, and quite familiar to anyone who sees a number of forearm fractures, but its mechanism, and the part played therein by the scaphoid, have not hitherto been clearly described and appreciated. The splitting-off of the piece of radius usually follows a line that runs obliquely upwards and outwards, as one would expect, seeing that the hand is abducted at the time of
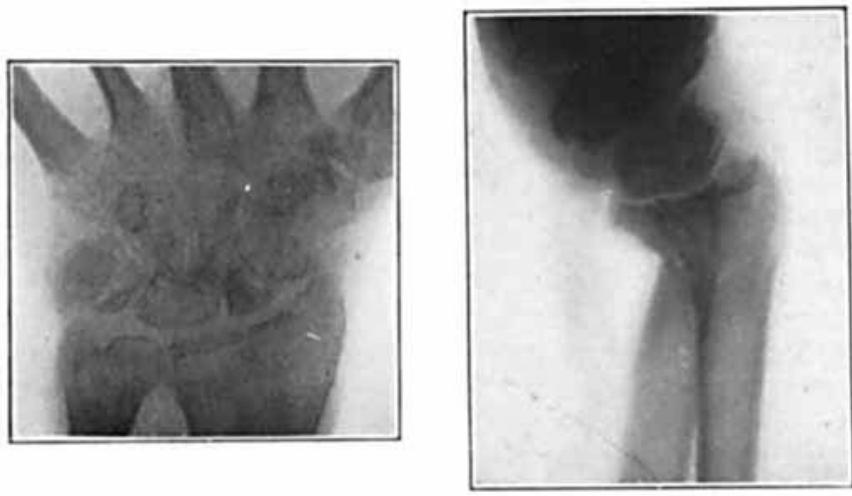

Fics. 20, 21.-Fracture of scaphoil, and of radius by scaphoid th sefere degree of Vialle's fracture) impact (Fig. 10). A lateral view, in these cases, will show that it is only the posterior lip of the radius that has been chipped off and displaced, and not its whole thickness. Sometimes the scaphoid breaks the radius as it strikes it, but escapes injury itself, as in Figs. 10 and 24 ; at other times both bones may be broken, as in Figs. 20 and 21 ; whilst on other occasions it is the scaphoid alone which gives way; no doubt this is partly due to its

being structurally weaker than either the os magnum or the radius.

Another variety of injury which oecasionally occurs in association with fracture of the scaphoid is fracture of the lower radial epiphysis. An example of this is seen in Fig. 7, which shows a definite vertical fracture without displacement through the lower epiphysis of the left radius; in this same patient there was produced simultaneously a fracture of the right scaphoid. Fig. 6 is another view of the same patient, taken with the two wrists side by side, and in this picture the existence of the fracture of the radial epiphysis is masked by the overlapping of the semilunar. This illustrates the importance of taking several views at various angles in difficult eases of fracture about the carpus.

Of those who have written about the mechanism of fracture of the scaphoid, Vialle, ${ }^{66}$ Princeteau, ${ }^{57}$ John B. Murphy, ${ }^{47}$ Jaboulay, ${ }^{32}$ and Destot ${ }^{15,16}$ have all taken the view that fracture was normally produced by a fall upon the abducted hand.

Fracture also occurs in adduction, or ulnar deflection, of the hand, but this is much less common. The usual form of violence is a backfire, so that we have a combination of ulnar deflection and forcible extension of the wrist-joint. This may produce sudden extreme tension of the external radioscaphoid ligament which is attached to the tuberosity of the bone, and this may be avulsed; the fracture is perfectly characteristic, and if one knows accurately the nature of the force applied, the existence of a

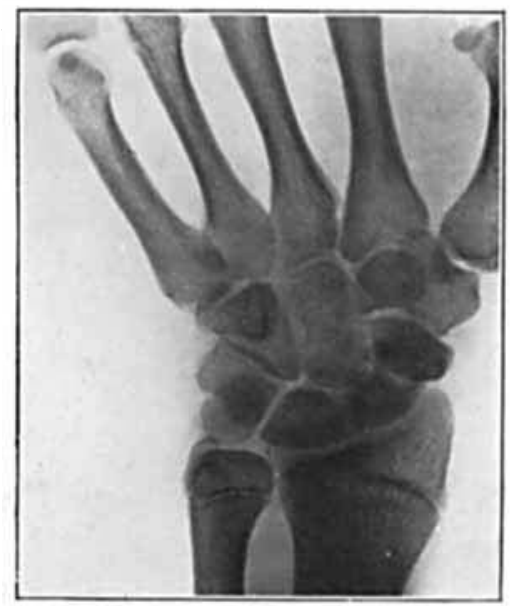

Tig. 22. - Wracture of the ' avulsed tuberosity' type, produced in udduction or nlnat deflection of carpus.

fracture of this type can be prophesied safely (Fig. 22). This is not at all a common form of fracture of the scaphoid; it has been described by J. B. Murphy, ${ }^{47}$ and also by Speese, ${ }^{64}$ thus making three types described by the latter author, viz., the transverse fracture with compression, the transverse fracture without compression, and the avulsed- 


\section{FRACTURES OF THE CARPAL SCAPHOID}

tuberosity type. When extension of the wrist is extreme, impaction may occur, or sometimes comminution, from compression. MeCarty ${ }^{39}$ alone thinks that ulnar deflection is the commonest mechanism of fractures of the scaphoid; he thinks that it is in this position that the ordinary 'snapped-waist' type is produced; he argues that in ulnar deflection plus hyperextension of the wrist, the scaphoid projects beyond the radius; the distal end is firmly fixed by ligaments, but the proximal fragment is mobile, being articular, and attached solely to the anterior annular ligament; therefore, he says, it is between the two that the bone gives way.

The third, and by far the rarest, mechanism consists in fracture of the scaphoid during hyperflexion of the wrist. In this position (Fig. 23), the two rows of carpal bones try to separate from one another; the tendency is for the first row of bones to move forwards and the second row backwards; the radiocarpal socket of the scaphoid is widely opened up, and as the bone is only supported behind by the tendons of the extensores carpi radialis longior and brevior, it follows that very often it becomes dislocated. Such a dislocation is, in fact, but the first stage of an intercarpal dislocation. In other instances, however, the

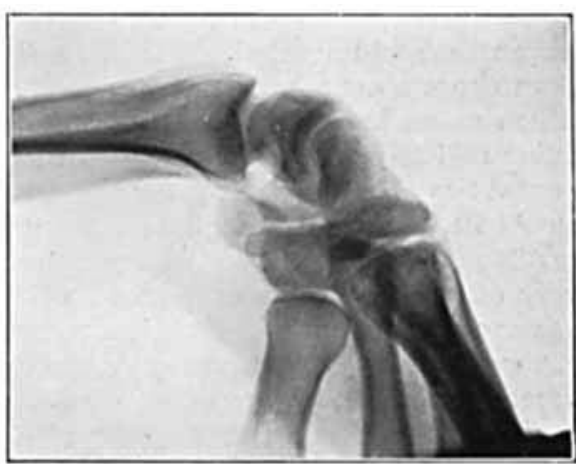

FIt. 28.--Nornal carpus in hyperllexion.

scaphoid is broken, the reason being that the bone in this position practically enters into the formation of both rows of the carpus; and it naturally follows that if one part tries to move in one direction, and the other part in the reverse direction, fracture must ensue. MacLennan ${ }^{40}$ has advanced the view that fracture of the scaphoid is usually produced during hyperflexion of the wrist, the lower or most posterior part of the joint receiving the main impact; in such a case there may be fracture of the lower part of the radius

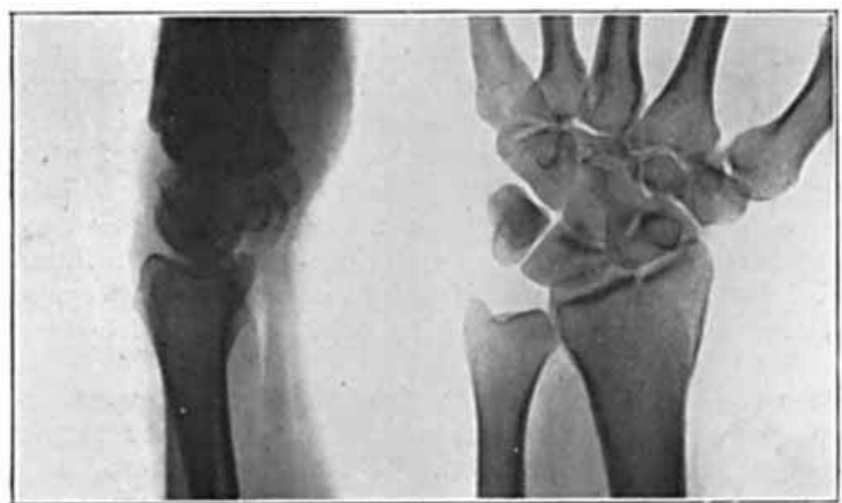

FIG. 24.-Fracture of radius by scaphoid. Vialte type. as well; Vialle ${ }^{66}$ and Vallas have recognized that fracture may be produced in this way, though they do not go so far as to say that it is the common way. In the Guy's series there has been no example of an injury of this type.

A knowledge of the mechanism of production of the several fractures of the scaphoid is of more than academic interest, for it will help to put us on our guard in their diagnosis. If, in examining cases of injury of the wrist, the likelihood of fracture of the scaphoid is always borne in mind, it is most improbable that such a fracture will ever be overlooked. Moreover, when the three cardinal signs of the fracture are present (viz., acute local tenderness, limitation of extension of the wrist, and cedema running up the dorsum of the wrist in its outer half, along the tendons), one can go further, and say that fracture of the scaphoid is actually present.

In all the recent cases that $I$ have seen, the diagnosis was definitely determined on clinical grounds before an $x$-ray picture was made, and in every case the diagnosis was confirmed. Furthermore, in no case has a diagnosis of fracture of the scaphoid ever 
been made without its being subsequently proved to be correct. In some cases, when the exact position of the hand at the time of impact can be elicited, one can go even further with the elaboration of the diagnosis, and predict from the mechanism the exact type of fracture that will be found.

A radiogram cannot be regarded as an infallible means of determining whether a fracture of the scaphoid has united or not, but in many cases it gives a very clear indication, and conclusions drawn from radiograms have frequently proved at operation to be quite correct. The commonest observation that one makes, in old fractures, is that they have remained ununited. More than three-quarters of all the old cases seen at the present time show non-union, and it appears, from a comparison of these cases with others in which union has taken place, that the greater part of their disability is due to the nonunion and the secondary results to which it gives rise. At operation it is found that the opposed surfaces of the pieces are not covered with smooth articular cartilage (as they would be in cases of true bipartite scaphoid), or with glistening fibrous tissue, or pseudocartilage, but that they are rough, and grate when rubbed together; moreover, there is very often some slight exuberance of callus upon the articular surfaces of the bone, and one can well imagine that such a rough material, scraping against the polished lower end of the radius, might cause a sudden twinge of pain, and make a man drop his tools. Sometimes there is definite evidence of chronic local arthritis of the joint in the shape of reddening and thickening of the soft parts, and a slight increase in the quantity and viscidity of the synovial fluid. Not only inside the joint, but around it also, there may be evidence of chronic irritation; if so, the prognosis is so much the more grave, for in this, as in all articular and para-articular fractures, the effect of the injury upon the joint is far more important than its effect upon the bone itself. It is often said that the chief reason for the non-union is deprivation of blood-supply, consequent upon the injury; but as the scaphoid normally receives its main blood-supply by way of the ligaments attached to it, and as these are seldom or never ruptured, it is rather difficult to see how this oft-repeated explanation applies.

Preiser $^{56}$ has contributed some interesting cases, in which he has shown that injury of the wrist may be followed by a central absorptive process going on in the scaphoid, the so-called 'rarefying osteitis', and a bone thus weakened may subsequently undergo pathological fracture; he suggests that the area of increased transradiancy seen in his $x$-ray photographs is due to absorption of the bone caused by rupture of the nutrient blood-vessels. His pictures show the central areas of absorption in these damaged, but unbroken, scaphoids very clearly, and one can easily imagine that after fracture a similar absorptive process might go on in the two halves of the bone, and lead to non-union and formation of a pseudarthrosis between them. In a few cases where the bone was excised a few days after fracture and carefully sectioned, it has been found that the middle of it was occupied by recent clot and liquid blood; in others, cystic degeneration has been described, and has been attributed to osteitis fibrosa following the injury.

Seeing that the normal nutrition of the scaphoid is by way of the ligamentous structures attached to it, and that these are rarely detached, it seems difficult to adopt a purely vascular lesion as the explanation of the frequent non-union. It seems much more likely that the fact of the fracture being entirely intra-articular has a great bearing upon the question. It is always bathed in excess of synovial fluid, and we know, from the analogy of other joint-injuries, that synovia does tend to exert an inhibitory action upon plastic processes. Indeed, in a normal healthy joint that is one of its most important protective functions. A third factor that plays a large part, no doubt, in producing non-union is undue mobility, for, as we have seen, most of these fractures are overlooked and not adequately rested.

One English author alone, as far as I can discover, advocates massage and mobilization from the very first; he says, writing in 1911, that carpal fractures occurring alone need no splint; that a large degree of freedom can be permitted from the outset; also, that bony union is the rule; that restitution of functional utility should be complete in three 


\section{FRACTURES OF THE CARPAL SCAPHOID}

weeks; that the formation of callus, given proper massage treatment, is unknown, and that even if bony union fails to occur, the patient suffers no inconvenience. The majority of surgeons hold diametrically opposite views. As regards the scaphoid, at any rate, it is held that early movements are one of the main causes, if not the most important cause, of non-union. And certainly, if we examine our patients' histories carefully, non-union does involve a very grave disability in the majority of cases ; the hand is painless if kept still, but is weak and untrustworthy in use. As Codman and Chase" say, "If the fracture remains ununited, the permanent disability is so great that it seriously interferes not only with the comfort of the patient, but with his ability to enjoy certain games and sports, and also, in the case of working men, it limits their working capacity, and hence their ability to earn their living". These writers found only three cases out of their series of thirty in which the wrist had been kept on splints for a time, and in all three bony union had taken place; and, in our own series, union has occurred in all the recent cases, after three or four weeks' rest upon a wooden or metal 'cock-up' splint. There is therefore considerable evidence to show that early movement, in the case of this fracture, is most prejudicial, and largely responsible for the production of the non-union. One must, of course, go a stage further with the argument, and inquire whether nonunion is the chief reason for the disability, and whether function is always good in those cases in which union has taken place. It will be found, on investigating the afterhistories of a series of patients, that function is always very much better in the united than in the non-united cases; in the writer's experience, the average time taken before a man was able to resume his full work was about eight weeks after the splints were removed, i.e., eleven to twelve weeks from the time of fracture. This may seem rather a long time, but it must be remembered that the majority of these patients are men whose occupations are laborious, such as that of stone-mason, 'bus conductor, wheelwright, etc. Moreover, twelve weeks is not a long time to spend on getting an injured wrist well, if the alternative is a joint that will be troublesome for the rest of the man's life.

As a routine treatment for a recent case, therefore, we strongly advocate preliminary splinting for three or four weeks, followed by mobilization and the employment of all the usual physiotherapeutic measures, such as whirlpool baths, contrast baths, or radiantheat baths. 'The writer has not been able to make out that the results of four weeks' fixation were any better than those of three weeks' splinting, and has therefore adopted the shorter period; and as regards the type of splint to be employed, a long 'cock-up' has been uniformly used, on the principle that if stiffness should ensue, it is better to have the wrist stiff in extension than in any other position, because that is its position of activity.

Absolute immobilization, in the strictest sense of the word, has not been attempted, nor has it been found necessary; resting the fingers and wrist upon a full-length 'cock-up' splint for three weeks has proved sufficient to ensure bony union; massage upon the splint has been employed after the first week, with the object of promoting absorption of inflammatory products, allaying spasm of muscle, and improving the blood-supply.

The principle of treatment, then, is very like that which we adopt in the much more common injury, the so-called separation of the lower humeral epiphysis; that is to say, we rest the parts at first, in order that over-production of bone within the joint may be avoided, keeping the joint meanwhile in the position of maximum usefulness; then, when the hyperæmia and other callus-promoting conditions have subsided somewhat, we proceed to restore mobility and function generally.

Generally speaking, the functional result is good in cases of fracture of the scaphoid when this principle is followed; in some few cases it is not, and in these as well as in a number of cases in which the initial treatment has been faulty, operation has been tried. A large number of such cases have been recorded, and the results seem to have varied enormously. Some authors say that their functional results have been perfect; others, that they have effected little or no improvement; and many take a sort of mid-position, 
claiming that if they have not cured their patients, they have at least given them more useful wrists. One writer, for instance, says, "Operation will ultimately give a good joint. It will not result in a wrist of normal strength and flexibility, but it will give a strong painless joint which is limited in the extremes of motion. When disability is pronounced and the hands are constantly used, the benefit from relief of pain may be sufficient to warrant risking a loss of strength".

There can be no doubt, at any rate, that the results of operation in late cases of fracture of the scaphoid often leave much to be desired, and it is quite impossible for a surgeon to guarantee restoration of function to a patient to whom he is proposing operation. In many of the published cases of excision of one or both of the fragments, there has remained a marked degree of stiffness of the wrist, or of loss of power ; several authors give some indication of the amount of permanent disablement when they say that they assess it as 30 per cent, or that the patient was only able to lift three or four kilos with the injured hand, whilst he could lift thirty to forty with the good hand. And there are undoubtedly many cases which have not been published, in which excision of one or both fragments has failed to effect much improvement. If relief of pain be all that the surgeon hopes to attain by operating, then the same result can be secured much more simply by providing the patient with a blocked-leather case, enclosing the forearm and wrist, by which means painful extension and sudden wrenches will be avoided.

The reason why operation has often failed and yet sometimes succeeds is not far to seek ; it is simply that it is often carried out too late. The disability, as we have seen, is due to the arthritis and peri-arthritis, and not to the non-union per se ; and if the fragments are not removed till the arthritis has been set up, and the arthritis persists, it is clear that such an operation must be foredoomed to failure. Operation can only succeed if it is done early. The proper course is to try splinting for three weeks, followed by massage, mobilization, and physiotherapy for anything up to three months; and if, by that time, function has not been restored and the patient still complains of pain on movement, it is probably wise to advise operation forthwith. Codman and Chase quote the case of a surgeon, in which early operation was performed with the most gratifying result; and Pförringer ${ }^{34}$ mentions another, in which excision of the whole scaphoid was followed by complete disappearance of pain, and the patient was enabled to lift and carry a $50-1 b$. weight without difficulty.

It is quite clear that late operations are almost always disappointing, and that, if operation is to be employed at all, it should be before the condition of chronic arthritis has been set up.

The technique of the operation is quite simple, and it can, if desired, be performed under local analgesia. An incision is made on the dorsum of the wrist, along the anatomical snuff-box; it is deepened, the radial nerve and artery being held aside; it goes down parallel with the tendon of the extensor carpi radialis longior, and to the inner side of it, care being taken to avoid opening its tendon-sheath; the bone having been removed, the skin is sutured, no attempt being made to close the joint-capsule. The wrist is bound up, and the patient is encouraged to make such movements as the bandages allow from the very first, and a little later on massage is instituted. It is apparently immaterial whether the whole scaphoid is removed, or only a part of it; the wrist is certainly not weakened in any perceptible manner by the removal of the whole bone, but the results of operation secm to have been as good when the proximal fragment alone has been excised.

The Lyons school of surgeons maintain that ablation of the scaphoid alone is 'quite inadequate', and that it has no effect upon the arthritis present-as one would expect. Vialle, ${ }^{66}$ and also Vallas, ${ }^{66}$ advocate formal excision of the wrist-joint, and describe their results as 'very good'. No details are given, however, and it is difficult to believe that such drastic treatment could really restore full function to a labouringman's right wrist.

From all that has been written about fractures of the scaphoid, and the many conflicting accounts that have been given of the results of various treatments, one fact 
emerges most clearly, viz., that all methods of late treatment are uncertain and unsatisfactory. It is evident that accurate diagnosis of the fracture in the first instance is essential to uniform success in treatment; and given that a surgeon knows that there is an intra-articular fracture present, it should generally be possible for him to devise such a plan of treatment as will result in bony union of the fragments without callus excess. In some few cases (e.g., those in which comminution of the bone is present), this may not be possible, and it is in these cases that early, or possibly primary, operation should be carried out.

The main object of this paper has been to show that fractures of the carpal scaphoid are really very characteristic, and have well-marked and almost pathognomonic physical signs; that they should always be diagnosed at the time when they occur, because it is only then that treatment is capable of restoring a useful degree of function; and, lastly, that failure to diagnose these fractures, though very common at the present time, is fraught with the most serious consequences for the patient, inasmuch as it means that he will almost certainly have a permanently crippled wrist, in spite of all the treatments that he may undergo.

\section{BIBLIOGRAPHY.}

1 Austra, Central States Med. Mag., Anderson, Ind. 1905, iii, 120.

2 Auvray, Gaz. des Hop., 1898.

3 BrCker, Surg. Gynecol. and Obstet., Chicago, 1906, iii, 21.

4 Bérard, Lyon méd., 1912, cxix, 481 .

5 BuedermanN, Kor.-Bl. d. allq. ärtzl. Ver., Thüringen, 1914, xliii, 317.

- Bijleveld, "De geisoleerde breuk van het os scaphoideum ", Nederl. Tijds. v. Geneesk., Amsterdam $1909, i, 1332$.

7 BLAv, Deut. Zeits. f. Chir., Leipzig, 1904, lxii, 445.

8 Bouchet, Thèse de Paris, 1834.

9 Castruccio, Arch. di Ortop., Milano, 1906, xxiii, 401.

10 Chaput, Bull. et Mém. Soe. de Chir. de P'aris, 1907, n.s., xxxiii, 294.

11 Codman and Chase, Ann. of Surg., 1905, 321, and 863 (report of 30 cases).

12 Conles, Boston Med, and Surg. Jour., 1913, clix, 88-90 (1. plate).

13 Cousin, Thèse de Lyon, $1897-8$ ( 6 cases).

14 DelbecQ, Thèse de Paris, 1888.

1 ś Destot, Lyon méd., 1904, cii, 529 ; Bull. Soc. de Chir. de Lyon, 1904, vii, 53 and 246. (Note : samo article, p. 67, gives the statistics of the various fractures of the wrist); Lyon. méd. 1904, ciii, 316 ; Ibid., 347 ; Ibid., 402 . Le Poignet et les Accidents de Travail, 1905.

16 Destot and Gallois, Lyon méd., 1905, civ, 633; Bull. Soc. de Chir. de Lyon, 1905, viii, 56.

17 Downes, Ann. of Surg., Philadelphia, 1908, xlvii, 72, (" plates, also discussion).

18 Duval and Ducastaing, Gaz. des Hôp., Paris, 1912, 1xxxv, 1247.

19 Ehemald, Arch. f. Orthop., Wiesb., 1906, iv, 276.

20 Fily, Ann. of Surg., 1903, xxxviii, 97 (1 plate); Ibid. 1905, xlii, 260 (1 plate); Med. Record, 1908, 1xxiii, 766.

21 Esprit, Dauphiné méd, Grenoble, 1909, xxiii, 131 (3 plates).

92. Flower, Holmes' System of Surgery, 1883.

23 Fullerton, D., Lancet, 1905, i, 1572.

24 Gabaglio, Policlinico. 1910, xvii (sez. chir.), 365, 381, 470 (2 plates).

25 GEIST, Jour.-Lancet, Minneap., 1916, xxxvi, 714

26 GUibour, Bull. de la Soc. anat., 1847 , xxii, 27 .

27 Hackmax, Wien. med. Presse, 1906, xlvii, 1409.

28 Hammond, Proc. Phil. Co. Med. Soc., 1904-5, xxv, 290.

29 Hinsch, Wien. med. Woch., 1910, 1x, 508, 573, 639: Arch. f. Orthop., Wiesb., 1910, ix, 47 (2 plates).

3e How W, Ugesk. f. Laeger, 1906 , t. R. xiii, 481 and 505.

31 Hue, Normandie méd., Rouen, 1906 , xxi, 337.

32 Jaboulay, Lyon méd., 1913, exxi, 699.

33 Japiot, Progrès méd., Paris, 1918, 3 s. xxxiii, 378.

34 JarJavay, Thèse inaug. de Paris, 1846.

35 Kanavel, Quart. Bull. N.W. Univ. Med. Sch. Chicago, 1908-9, x, 8.

36 JoNes, RoBert, Lancet, 1909, i, 1714.

37 LILIenfeld, Arch. f. klin. Chir., Berlin, 1903, lxix, 1158 (2 plates).

38 Lumrìre, Bull. et Mém. Soc. anat. de Paris, 1919, lxxxix, 399.

39 MCCARTY, Surg. Clin. Chicago, Phil., 1919, iii, 371 .

ao Maclennan, Brit. Med. Jour., 1911, ii, 1089.

41 Maisonneuve, Mém. de la Soc. de Chir., ii.

42 Marix, Soc. de Méd. et de Chir. de Bordeaux, 1910.

4 Mayer, Soc. imper.-royal. des Méd. de Vienne, 1910

44 Meyer, Monats. f. Unfallheilk, Leipzig, 1909, xv, 361.

45 Mish, Khiruzgia, Moscow, 1908, xxiv, 308. 
4 Mouchet, Bull. et Mém. Soc. Anat. de Paris, 1908, lxxxiii, 130 : Rev. d'Orthop., Paris, 1914,3 s., v. 201.

47 Murphy, John B., Surg. Clin. Chicago, 19l5, iv, 385 (3 plates).

48 Nogitr, Lyon méd., 1914, cxxii, 139 (1 plate).

49 Okuniewski, Allg. mil.-artzl. Zeit., Wien, 1906, xlvii, 42.

50 Orton, Proc. Roy. Soc. Med., London, 1907-8, i (Elec.-Ther. Sec.), 62.

-1 Pagenstecher, Münch. med. Woch., 1903, 1916-18.

i2 Paul, Nancy, 1907, 106 pp. 8vo.

53 Petresohn, Berl. klin. Woch., 1908, xlv, 409.

34 Pförringer, Forts, a.d. Geb. d. Röntgenstrahlen, Hamburg, 1912, xix, 69

5s Pothérat, Bull, et Mém. Soc. de Chir., Paris, 1909, n.s., xxxv, 765 (1 plate)

56 Pretser, Forts. a.d. Geb. d. Röntgenstrahten, Hambirg, 1910, xv, 189, 197 (1 plate); Zentralbl. f. Chir., Leipzig, 1910, xxxvii, 929.

57 Princeteau, Jour. de méd., Bordeaux, 1911, xli, 217.

58 Reynard, Lyon, 1904, 51 pp. 8vo.

59 Riede, D., Wien. klin. Woch, 1906 , xix, 1520.

tio RIEFfes, Traité de Chimurgie, by le Dentu and Delbet.

61 Russ, Ann. of Surg., 1905 , xli, 265.

62 Ruthenford, Glasgow Med. Jour, 1891, 311.

6s Schultz, Deut. Zeits. f. klin. Chir., Leipzig, 1909, 141-157.

64 Speese and Skillere, Internat. Clinics, Phil., 1917, 27, s. ii, 266 ; Ibid., 263 (1 plate).

65 Totski, Kharkov Med. Jour., 1913 , xv, 190 (1 plate)

6 6 Vialee, Lyon méd., 1904, cii, 315; Bull. Soc. de Chir. de Lyon, 1904, vii, 11 ; Lyon méd., 1904, ciii, 374: Arch. de Méd. et Pharm. Mil., Paris, 1904, xliv, 253.

67 Virchow, Med. klin., Berlin, 191 , vii, 929.

68 Wolff, Deut. med. Woch., Leipzig u. Berlin, 1903, xxix (Ver.-Beil.), 338 ; Arch. f. klin. Chir., Berlin, 1905 , xliii, 634 .

69 Young, A., Glasgow Med. Jour., 19I4, 1xxxii, 124. 